\title{
OPEN A metabolomic study of Gomphrena agrestis in Brazilian Cerrado suggests drought-adaptive strategies on metabolism
}

\author{
Geraldo Aclécio Melo ${ }^{1 凶}$, Ilka Nacif Abreu ${ }^{2}$, Maíra Baista de Oliveira ${ }^{1}$, \\ Ilara Gabriela Frasson Budzinski ${ }^{2}$, Lucinélia Vieira Silva ${ }^{1}$, Marcio Antônio Silva Pimenta ${ }^{1}$ \& \\ Thomas Moritz ${ }^{2,3}$
}

Drought is the main factor that limits the distribution and productivity of plant species. In the Brazilian Cerrado, the vegetation is adapted to a seasonal climate with long- and short-term periods of drought. To analyze the metabolic strategies under such conditions, a metabolomic approach was used to characterize Gomphrena agrestis Mart. (Amaranthaceae) a native species that grows under natural conditions, in a rock-field area. Roots and leaves material from native specimens were sampled along different seasons of the year and LC-MS and GC-MS analyzed for multiple chemical constituents. The datasets derived from the different measurements were combined and evaluated using multivariate analysis. Principal component analysis was used to obtain an overview of the samples and identify outliers. Later, the data was analyzed with orthogonal projection to latent structures discriminant analysis to obtain valid models that could explain the metabolite variations in the different seasons. Two hundred and eighty metabolites were annotated, generating a unique database to characterize metabolic strategies used to cope with the effects of drought. The accumulation of fructans in the thickened roots is consistent with the storage of carbons during the rainy season to support the energy demand during a long period of drought. The accumulation of Abscisic acid, sugars and sugar alcohols, phenolics, and pigment in the leaves suggests physiological adaptations. To cope with long-term drought, the data suggests that tissue water status and storage of reserves are important to support plant survival and regrowth. However, during short-term drought, osmoregulation and oxidative protection seems to be essential, probably to support the maintenance of active photosynthesis.

The Cerrado (Neotropical savanna) covers about 2 million $\mathrm{km}^{2}$ of Central Brazil and represents about $23 \%$ of the land surface of the country ${ }^{1}$. It is one of the richest and most diverse savanna worldwide and considered one of 34 global hotspots for biodiversity ${ }^{2}$. A striking feature of the Cerrado is the seasonal climate with a dry season that extends from May to September and a rainy season with precipitation ranging from 800 to $1800 \mathrm{~mm}(90 \%$ between October and April) ${ }^{3}$. In the rock-field formations of the Cerrado, the soil is shallow and sandy with low water-holding capacity ${ }^{4-6}$. The rock-field vegetation is characterized by herbaceous shrubs, with a predominance of endemic and rare species with nutritional and biological specializations to acquire resources from the soil and survive under high irradiance, strong winds, and low water availability in the soil ${ }^{5,7,8}$. Because of the specific climate (long and short periods of drought), soil physical characteristics, and adapted native flora, the rock fields of Cerrado are a natural resource for studying plant traits and responses under limited water conditions.

All plant species have varied tolerance or resistance to drought, depending on their phenological, morphological, physiological, and biochemical characteristics. All these adaptive mechanisms allow the plants to escape or tolerate the stress condition by either avoiding, reducing, or resisting dehydration ${ }^{9-11}$. The drought stress in plants occur when either the water supply to their roots becomes limiting or when the transpiration rate becomes too

${ }^{1}$ Departamento de Biologia Geral, Universidade Estadual de Montes Claros, Montes Claros, MG 39401-089, Brazil. ${ }^{2}$ Department of Forest Genetics and Plant Physiology, Swedish University of Agricultural Sciences, Umeå Plant Science Centre, 90183 Umeå, Sweden. ${ }^{3}$ Novo Nordisk Foundation Center for Basic Metabolic Research, Faculty of Health and Medical Sciences, University of Copenhagen, Copenhagen, Denmark. ${ }^{\circledR}$ email: geraldo.melo@unimontes.br 
intense that the system can not reach a balance ${ }^{9}$. At these points, the stress starts affecting the water functions, early, reducing the water potential and turgor, what lead to reduction in cell enlargement and culminating in reduced growth and the potential of growth. Subsequently, passive or active stomata closure will limit $\mathrm{CO}_{2}$ supply for photosynthesis ${ }^{12-14}$, what by itself is sufficient to constrain carbon assimilation and to starts a network of effects in process that are carbon dependent. Besides, under day light, with the reduction of the flux of electrons for carbon assimilation, it may lead to overproduction of reactive oxygen species ${ }^{15,16}$, that in turn will cause more constraints to the already reduced photosynthetic capacity of the plant. Depending on the intensity and duration of the stressing condition more constraints can be imposed and the plant can be put to death.

In the Cerrado rock-fields, where the species can experience water stress in different extent, it was already reported in the plants characteristics to deal with the water availability, such as the presence of aerial roots with velamen or pseudocaules that play a role in the access of moisture of dew and rain ${ }^{17}$. In some specie, leaves in rosette forms, as in bromeliads, allow water retention ${ }^{18}$ and in many other plants water-secreting structures and trichomes are also common, and may play a role in atmospheric water uptake ${ }^{19}$. Thickened underground organs that accumulates reserves, mainly carbohydrates, are also common in shrubs and herbs and may play an important role in water storage and maintenance of the water status ${ }^{20-23}$. The type and content variation along season of fructans, are mentioned to be important in the osmoregulation process ${ }^{20,22}$. Also, it is a significant source of nutrients and carbon to be used during regrowth after drought ${ }^{23,24}$.

Global climate changes have led to concerns regarding the effects of drought on plant development and agricultural and natural ecosystems ${ }^{25,26}$. Changes in temperature and rainfall patterns could result in limited water for plant growth in some regions, especially agricultural lands ${ }^{27,28}$. Studies need to be performed to understand how known strategies were established along with plant evolution, how plants will be affected by and respond to climate change, as well as how we can use this information to develop and manage agriculture in the future, for example, develop varieties that can maintain optimum yield levels even under stress conditions and establish irrigation management $\mathrm{t}^{29,30}$.

Here, to investigate metabolic patterns that can be associated with the drought in plants growing under rockfield conditions, several metabolomic approaches were used to characterize the metabolite profile of Gomphrena agrestis Mart. (Amaranthaceae), a native species ${ }^{31}$ along different season in 1 year. The goal questions were: (1) How is the availability of water in the soil along seasons? (2) Do the plants have the water status changed along seasons and can it be associated with the water availability in the soil? (3) What are the main changes in metabolite patterns in the plants? A database of 280 metabolites was generated, which include primary and secondary metabolites, hormones, and lipids, which was used to understand metabolic adaptations under short- and longterm periods of limited water conditions in rock-fields.

\section{Results}

Water status of the soil and plants. The precipitation data from the region are shown in Supplementary Table 1. From September to November (2013) and February to July (2014), great variations in rainfall were observed in the region, with the highest index in April (75 mm of rain). In February, even in middle of the rainy period, a reduction in rainfall rates was detected $(13 \mathrm{~mm}$ in February). The past data for the region have shown lower precipitation rates in February (INMET, 2017), leading to a short dry period during the rainy season (this period is popularly called "Veranico"). In July, which is a part of the dry season, no precipitation was recorded.

The soil moisture was positive correlated $(p<0.05)$ with the rainfall recorded for the period and ranged from 0.4 to $17.3 \%$ (Fig. 1). Interestingly, during the rainy season (from November to April), a decrease in the percentage of soil moisture, in February, matches with the Veranico period. In the months that comprise the dry periods, soil moisture was $0.4 \%$ in early September 2013 and $1.05 \%$ in July 2014.

Phenology. The predominant phenological stage annotated for the species was compiled and represented in Fig. 2. At the end of the dry period, in early September, the plants were characterized in a dormant state, showing senescent floral branches and older leaves. In the DR period in October, the plants entered the sprouting state, with emission of new branches and leaves. In the Veranico period in February, presence of inflorescences with reddish floral parts was observed. In the rainy period in April, the fruiting phase was characterized by the presence of inflorescences with senescent and paleaceous floral parts. The fruiting phase lasted until May in the DR period, and the senescence of the floral branches was remarkable. In July, at the beginning of the dry period, the plants entered dormancy. In the dormant state, the younger leaves on the branches of the plants were still green.

Abscisic acid content. In Fig. 3, the relative water content (RWC), abscisic acid (ABA) content, and Sm are summarized as an average of the samples of the $\mathrm{D}$, dry period; $\mathrm{RD}$, transition from dry to rainy period; $\mathrm{V}$, veranico period; $\mathrm{R}$, rainy period; and $\mathrm{RD}$, transition from rainy to dry period. No correlation was observed between Sm and leaf and root RWC values of the plants. Nevertheless, in the Veranico period, RWC of the leaves was slightly lower when there was a decrease in Sm (Fig. 3A).

Abscisic acid (ABA) content in the roots and leaves was measured because of its important role in plant responses to drought and other abiotic stresses (Fig. 3B). The general pattern of ABA accumulation was similar in the leaves and roots; however, ABA content was significantly higher in the leaves (Tukey's test, $p<0.05$ ) in the $\mathrm{V}$ period than in the $\mathrm{DR}$ and $\mathrm{R}$ periods.

Metabolic profiling. To obtain information on the metabolic phenotypes of G. agrestis grown under natural conditions in a rock-field area of the Cerrado in the dry and rainy seasons, we performed a multi-metabolomic analysis of the leaves and roots. The datasets derived from different measurements were combined and evaluated using multivariate analysis. Principal component analysis (PCA) was used to obtain an overview of the samples 


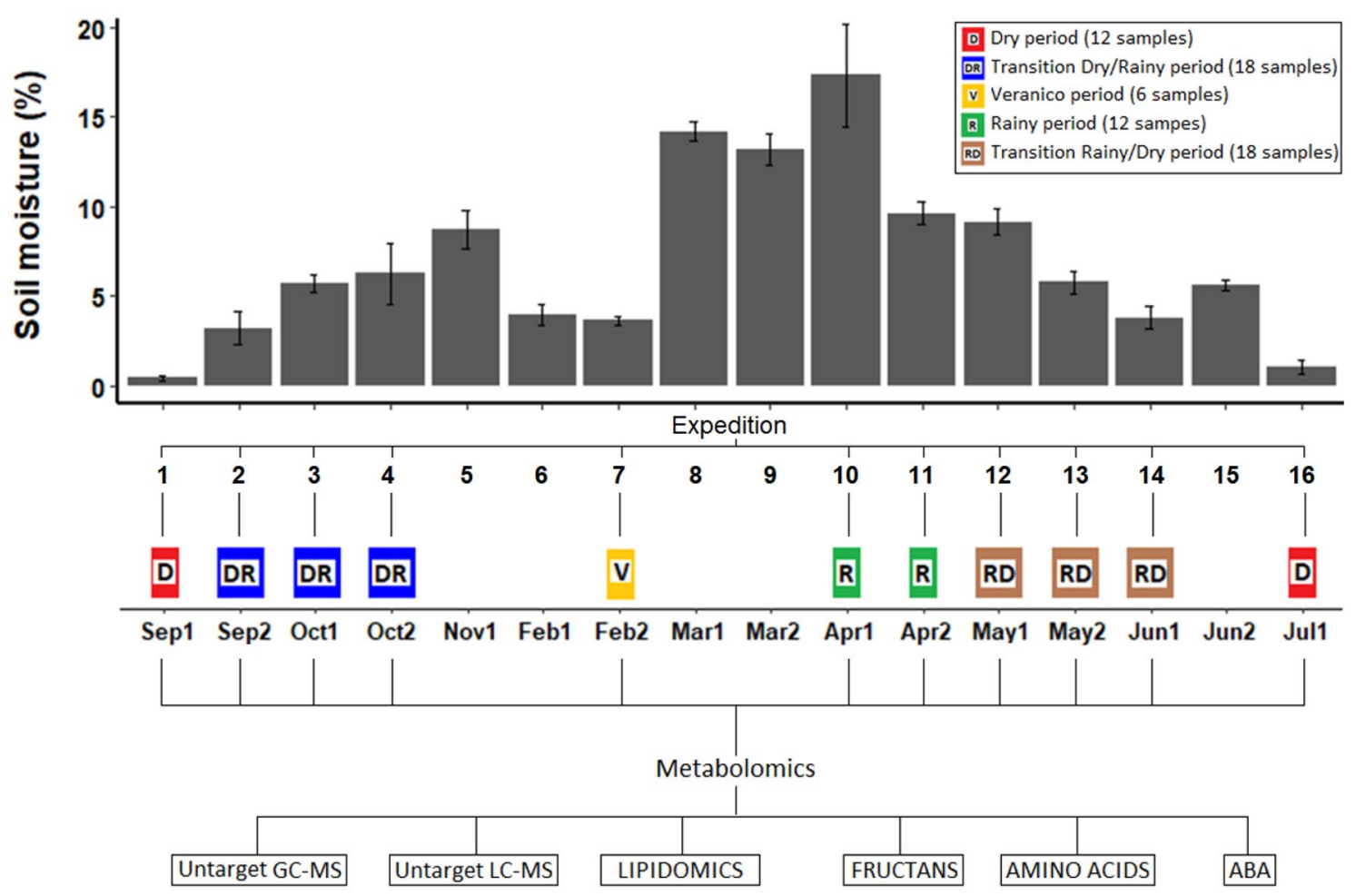

Figure 1. Design of sampling and sample grouping for the metabolomic analysis. The groups are as follows: $\mathrm{D}$, dry period (12 samples, red color); DR, transition from dry to rainy period (18 samples, blue); V, veranico, a short dry period during the rainy period (6 samples, yellow); R, rainy period (12 samples, green); and RD, transition from rainy to dry period (18 samples, brown). Below, months of the year and the number of the sample in the corresponding month. Soil moisture was used to select samples for metabolomics.

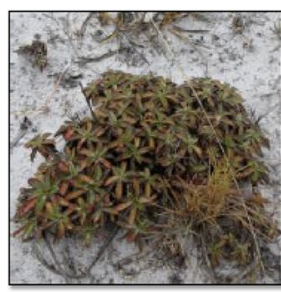

D

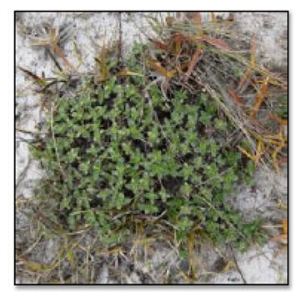

DR

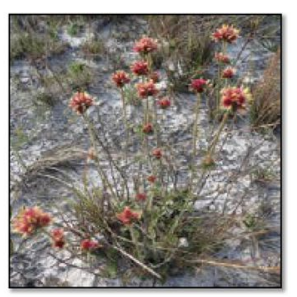

V

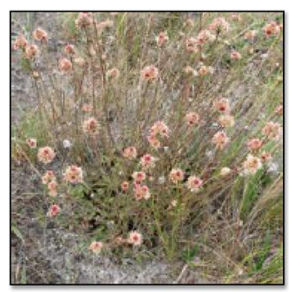

$\mathbf{R}$

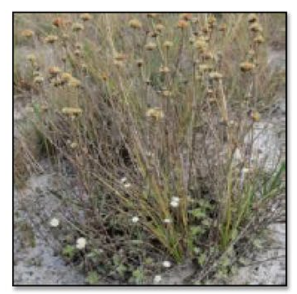

RD

Figure 2. Phenological characterization of Gomphrena agrestis Mart. (Amaranthaceae) in a rock-field area in the dry and rainy seasons. $\mathrm{D}$, dry period; $\mathrm{RD}$, transition from dry to rainy period; $\mathrm{V}$, veranico period; $\mathrm{R}$, rainy period; and $\mathrm{RD}$, transition from rainy to dry period.

and identify outliers (data not shown). Later, the data was analyzed with orthogonal projection to latent structures discriminant analysis (OPLS-DA) to obtain valid models that could explain the metabolite variations in the different seasons. From the generated loading plots, the metabolites were filtered by variable importance in the projection (VIP) (cutoff $\geq 1$ ) and listed. On the basis of the selected VIP metabolites, OPLS-DA score plots of the leaves and roots are shown in Fig. 4. To validate the strategy, several pair-wise OPLS-DA models were calculated between the groups by using the selected metabolites (Supplementary Table 2). Because all comparisons resulted in valid models, the distinct metabolites were clustered, and the heatmaps (Fig. 5A,B) show a global metabolite profile of the leaves and roots of G. agrestis in different seasons.

The metabolites derived from the untargeted approach with GC-MS and LC-MS analyses were systematically annotated (Fig. 5A,B, as described in the "Material and methods"). The combination of targeted and untargeted approaches allowed us to have a significant coverage of all major metabolite classes that could characterize the plant adaptation to the environmental changes, resulting in the annotation of 280 metabolites (Supplementary Tables 3, 4, 5, 6, 7 and 8); 215 were detected in the leaves and 195 in the roots.

For better interpretation, the annotated metabolites were clustered using a non-hierarchical analysis according to their metabolite class (Fig. 6). As expected, different metabolite patterns were observed in the leaves and roots of G. agrestis. The analysis of the leaves showed a unique pattern for Veranico samples, and the accumulation of 
A)

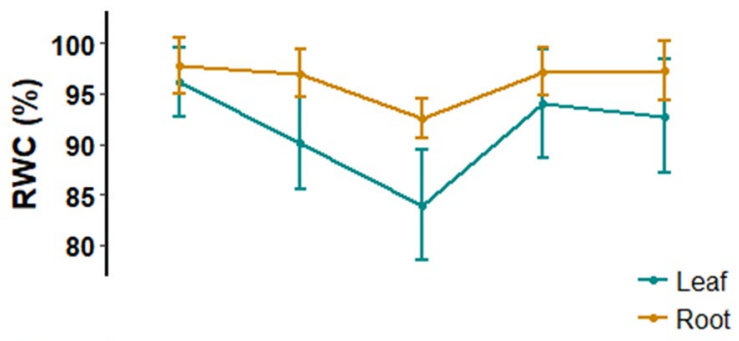

B)

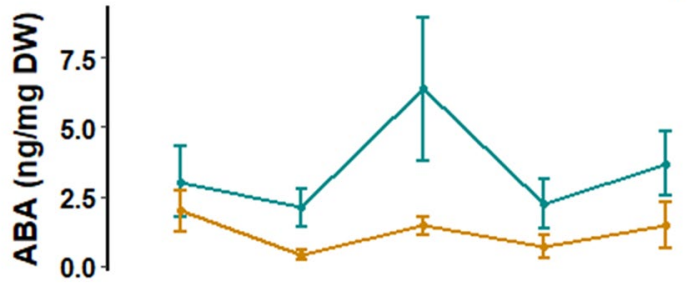

C)

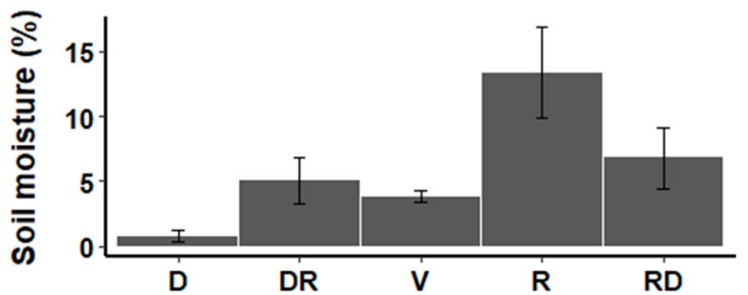

Figure 3. Relative water content (RWC) - (A) abscisic acid content (ABA) - (B) and Soil moisture-(C) in leaves and roots of Gomphrena agrestis Mart. in a rock-field area in the dry and rainy seasons. $D$ dry period, $R D$ transition from dry to rainy period, $V$ veranico period, $R$ rainy period, $R D$ transition from rainy to dry period. Performed using R-software version 3.4.166.

A

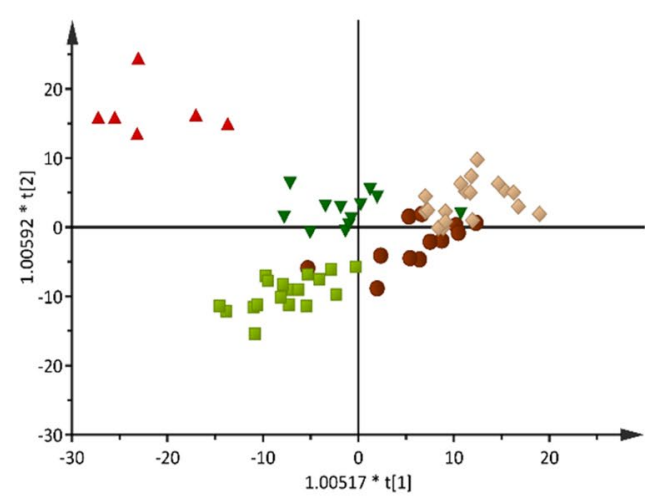

B

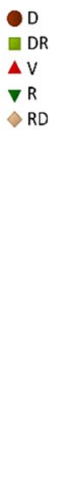

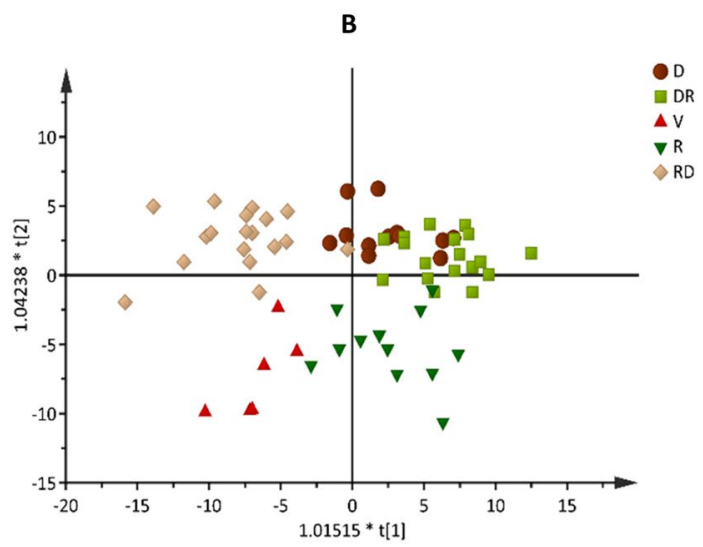

Figure 4. Multivariate data modelling: Score plot of orthogonal projection to latent structures discriminant analysis (OPLS-DA) performed on metabolites in leaves (A) and roots (B) of Gomphrena agrestis Mart. in a rock-field area in the dry and rainy seasons. Sample groups: $D$ dry period, $R D$ transition from dry to rainy period, $V$ veranico period, $R$ rainy period, $R D$ transition from rainy to dry period.

organic acids, sugars, galactolipids, phenolics, and chlorophyll degradation products were observed. Interestingly, contrasting accumulation of some sugars, phosphocholine (PC), triacylglycerolipids (TAG), and galactolipids (MGDG and DGDG) were verified between Veranico and RD. Accumulation of amino acids and pigments (chlorophylls and ketocarotenoids) was observed in the leaves during the transition from drought to rainy season. In the roots, a distinct fructan pattern was observed: plants grown during Veranico and rainy accumulated fructans containing less than 10 units of fructose, and plants grown during dry and DR accumulated more complex fructans. In general, higher levels of amino acids were observed in the DR and R seasons.

Drought-discriminating metabolites. The impact of water availability in the soil on the leaves and roots of G. agrestis grown in the rainy, dry, and Veranico seasons is shown in Figs. 7 and 8 and Supplementary Tables 9 and 10. In general, changes in the metabolism of sugar, specially fructans, lipids, amino acids, and phenolics 
A

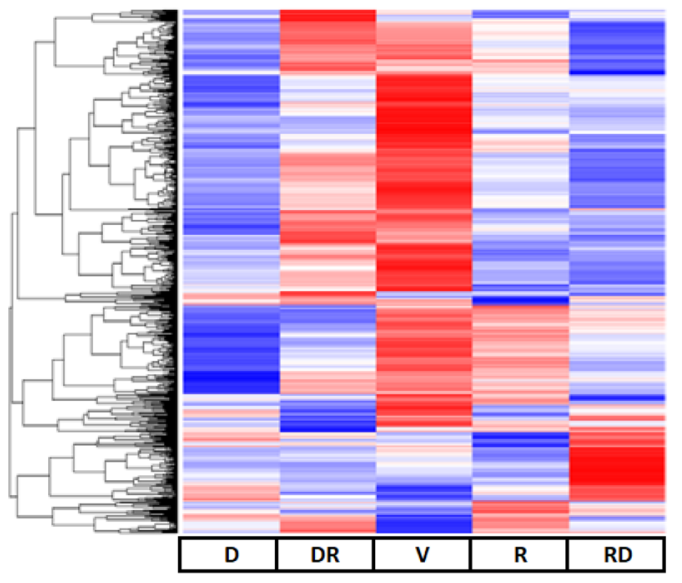

Leaf
B

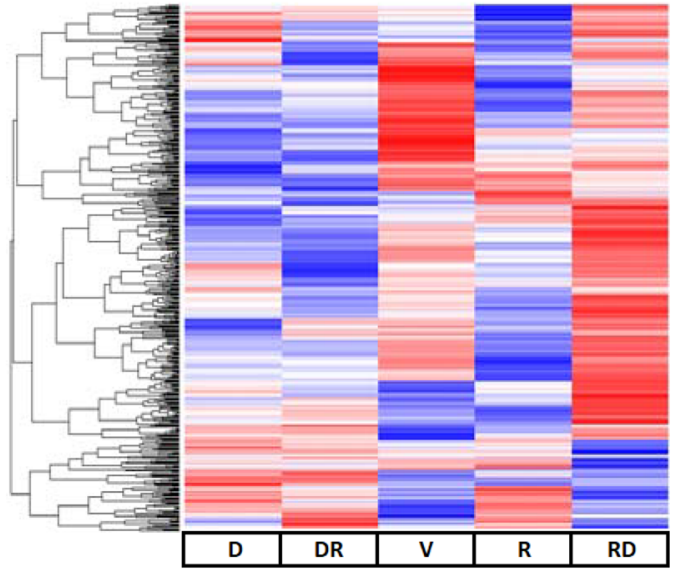

Root

Figure 5. Heatmap visualization from a cluster hierarchical analysis of leaf and root metabolites of Gomphrena agrestis Mart. in a rock-field area in the dry and rainy seasons. $D$ dry period, $R D$ transition from dry to rainy period, $V$ veranico period, $R$ rainy period, $R D$ transition from rainy to dry period. Performed using R-software version $3.4 .1^{66}$.

A

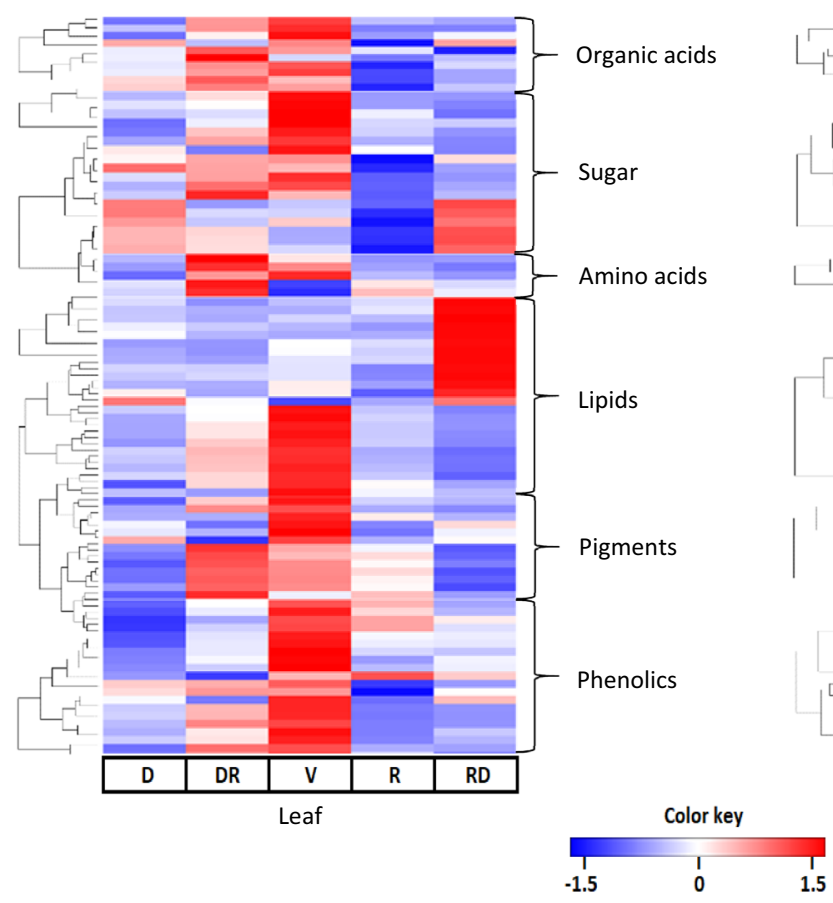

B

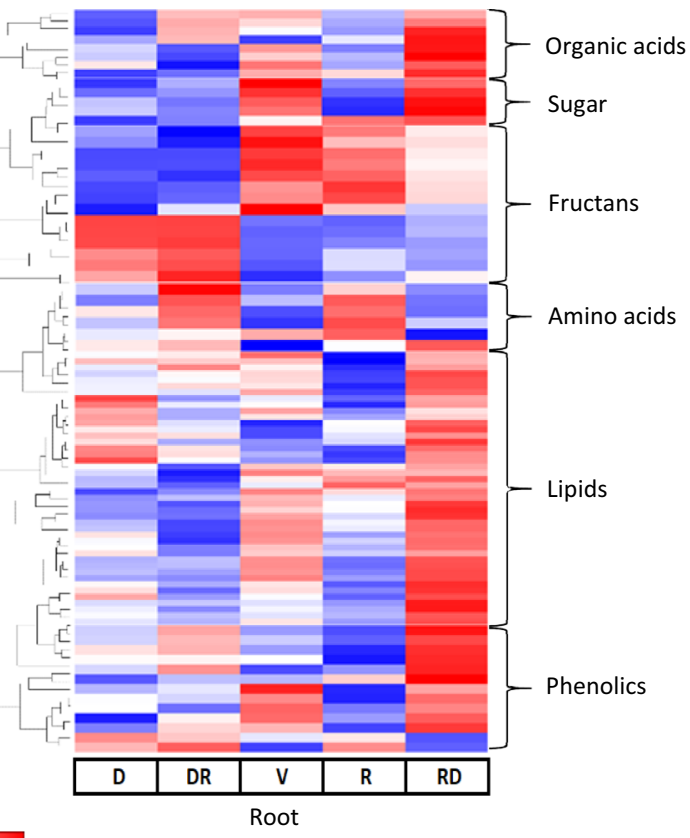

Figure 6. Heatmap visualization from a cluster hierarchical analysis of annotated metabolites of leaf and root of Gomphrena agrestis Mart. in a rock-field area in the dry and rainy seasons. $D$ dry period, $R D$ transition from dry to rainy period, $V$ veranico period, $R$ rainy period, $R D$ transition from rainy to dry period. Performed using R-software version 3.4.1 ${ }^{66}$.

were observed in the roots. The accumulation of fructans containing 15_DP, 16_DP, and 17_DP units of fructose and glycerolipids MGDG (36:3), DGDG (36:5), PC (33:0), TG (50:2), TG (48:2), and TG (53:3) was pronounced during the dry season, which is in contrast to the reduced levels of fructans containing small units of fructose and amino acids GABA, phenylalanine, tyrosine, and valine during the rainy (R) season. However, during Veranico, accumulation of the sugars lactose, sorbitol, and mannitol, fructans 2_DP and 3_DP, lipid TG (55:4), and the phenolic 3,4-dihydroxybenzoic acid was observed, and a decrease in the amino acids valine, phenylalanine, tryptophan, and glycine betaine was observed. The metabolism of sugars, lipids, phenolics, and pigments 


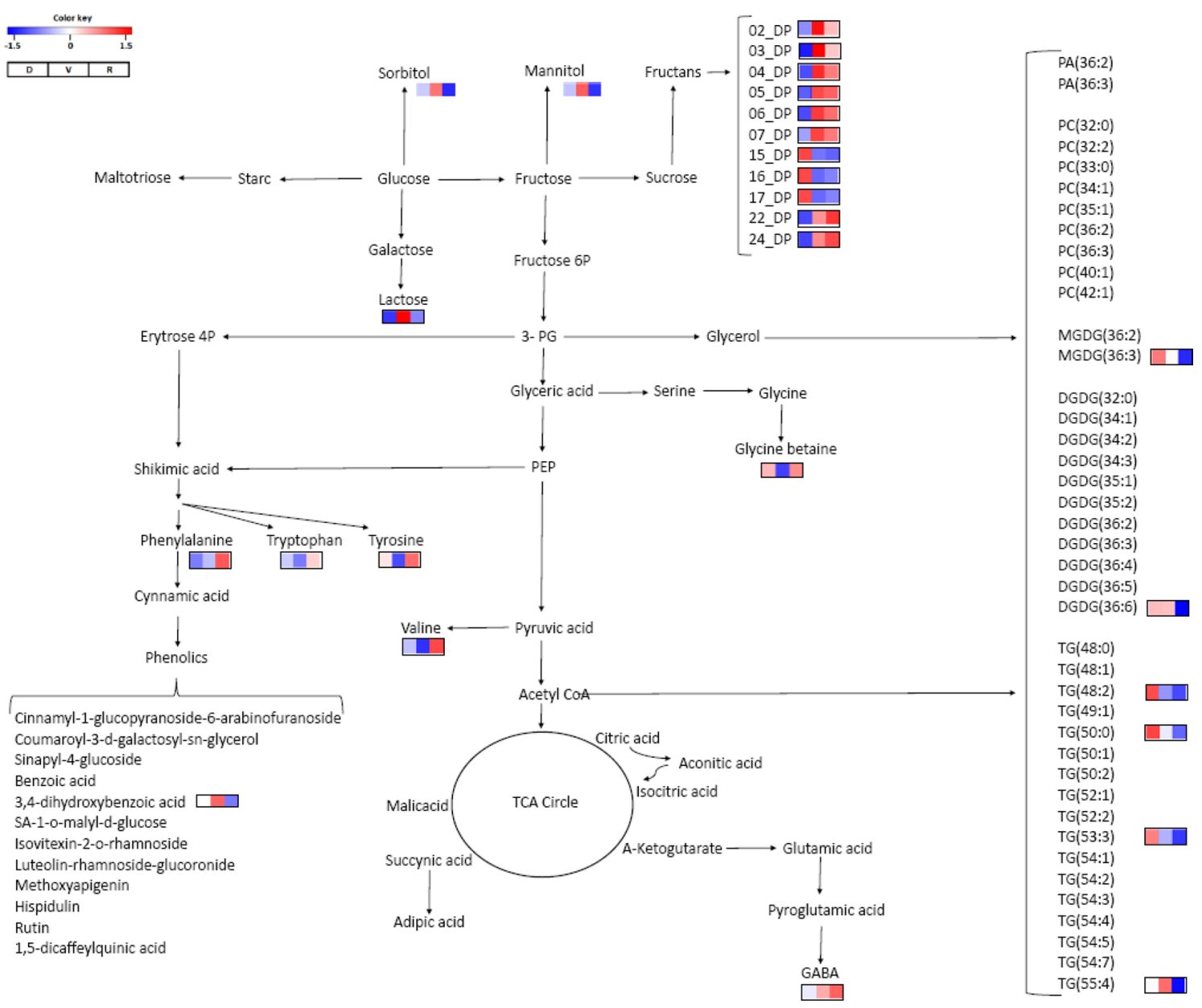

Figure 7. Metabolic pathway indicating the annotated metabolites of Gomphrena agrestis Mart. roots in a rockfield area in the dry and rainy seasons. Bars indicate relative intensity of metabolites, with pairwise comparisons of higher changes between the sample groups $\mathrm{R} \times \mathrm{D}$ and $\mathrm{R} \times \mathrm{V}$. $D$ dry period, $V$ veranico period, $R$ rainy period. $D P$ degree of polymerization - number of fructose residues in the molecule.

was affected in the leaves in the dry, Veranico, and rainy seasons (Fig. 8), with pronounced accumulation of galactolipids, xanthophylls, chlorophyll intermediates, and several classes of phenolics such as phenylpropanoids, benzoic acid, and flavonoids in Veranico. Although the dry and Veranico seasons were characterized by low water availability in the soil, the metabolism of G. agrestis responded differently.

\section{Discussion}

In the Brazilian Cerrado, the vegetation is adapted to a seasonal climate with short and long periods of drought. This condition causes the local species to experience low water availability during specific periods of the year. In the present study, the water status in the soil of a rock-field area in the Cerrado changed from low to high moisture, which directly impacted the water status of plants collected from the same area during different months of the year (Figs. 1 and 3). Endemic species, like Gomphrena, in the Brazilian Cerrado are adapted to such water variations and can survive via different and perhaps unknown physiological strategies. In general, plant adaptation can include changes in the developmental stage and phenology of plants obtained during different seasons (Fig. 2).

The global analytical approach used to analyze G. agrestis allowed us to obtain a unique metabolite fingerprint of plants growing under natural conditions in Cerrado's dry (D: July and September), dry-rainy (DR: end of September and October), Veranico (V: February), rainy (R: March and April), and rainy-dry (RD: May and June) seasons. The results provide several hints about how this endemic specie can tolerate such drastic changes in the soil water availability throughout the year. The drought stress on the plants occur when either the water supply to their roots becomes limited or when the transpiration rate becomes too intense and causes a system imbalance ${ }^{1}$. In both situations, the stress starts to affect the water functions, culminating in reduced growth. Here, the leaves and roots of G. agrestis showed reduced RWC during Veranico, resulting in an increase in ABA content (Fig. 3B). The results suggest that $G$. agrestis controls the stomatal movement as a strategy to keep the tissues hydrated or maintain the $\mathrm{CO}_{2}$ supply for photosynthesis, as observed in many other species ${ }^{32-36}$. The maintenance of open stomata can lead to a greater loss of water and consequently dehydration. However, if the soil is sufficiently moist or if the moisture is recovered soon, it is easy for the plant to replenish water and maintain both photosynthesis 


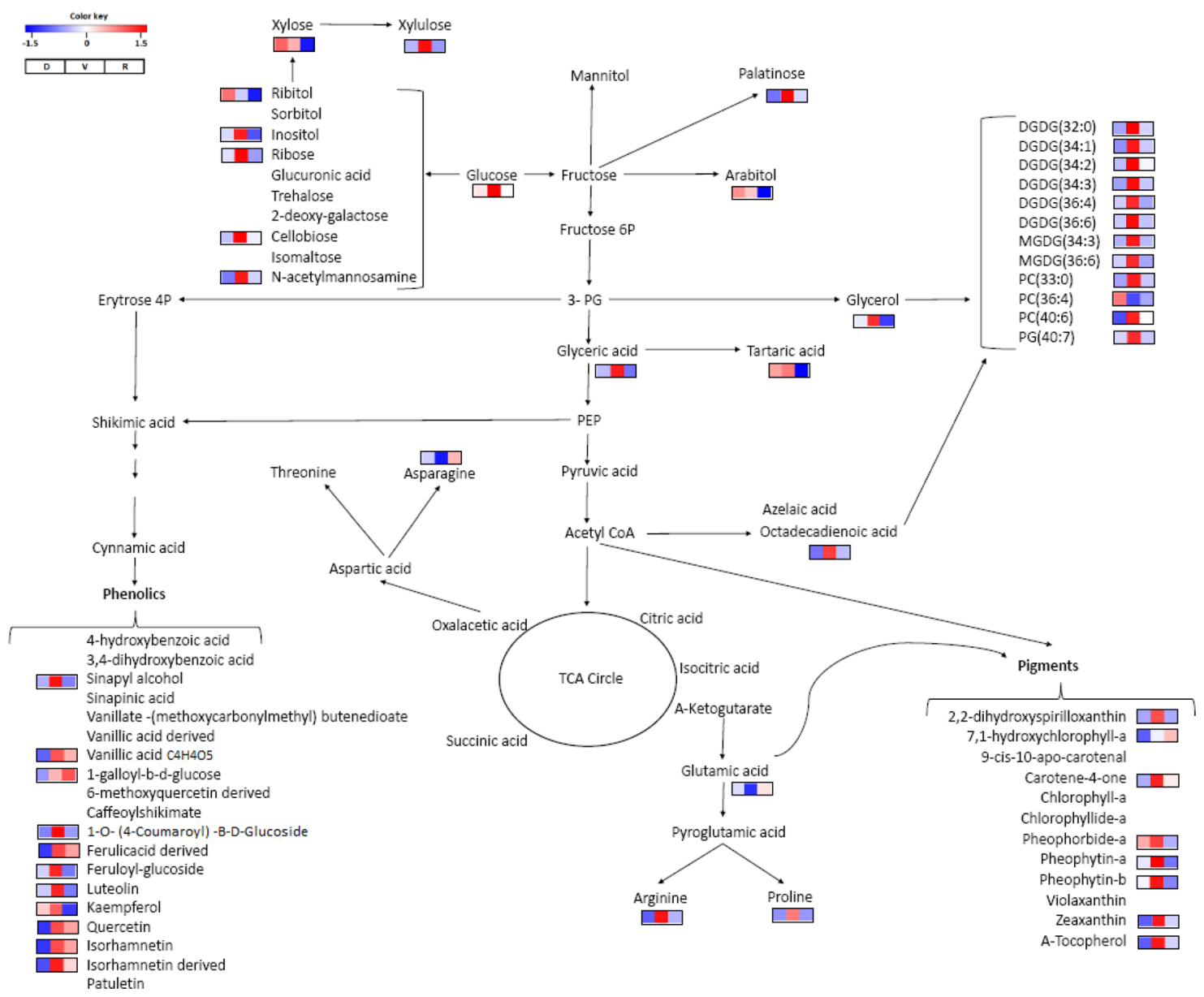

Figure 8. Metabolic pathway indicating the annotated metabolites of Gomphrena agrestis Mart. leaves in a rockfield area in the dry and rainy seasons. Bars indicate relative intensity of metabolites, with pairwise comparisons of higher changes between the sample groups $\mathrm{R} \times \mathrm{D}$ and $\mathrm{R} \times \mathrm{V}$. $D$ dry period, $V$ veranico period, $R$ rainy period.

and the growth rate. Because of the physical characteristics of the rock-field soil (shallow and sandy) and lower precipitation rates during the Veranico period, the soil moisture decreases quickly and probably limits the water availability for the plants (Fig. 3C). ABA has an important role under stress conditions, especially during drought ${ }^{6,37,38}$. In the present study, we found a pronounced increase in ABA levels in the leaves during Veranico.

Generally, the root system is affected to the greatest extent when there is water scarcity or the availability of water is inconsistent ${ }^{39}$. The fact that the ABA levels were not significant in the roots suggest that Gomphrena plants have other alternatives to compensate for the drought. Fructans in the tissues may act as osmotic solutes to maintain the water status of tissues ${ }^{28}$. Our results support their suggestion because we found increased levels of fructans containing up to 8 units of fructose during the Veranico season (Fig. 7). Similar results were obtained by $^{40}$, who reported no changes in the RWC in the roots of Gomphrena marginata (also growing in a rock field) during the dry period, suggesting that accumulation of fructans could result in osmoregulation. Similar results were found in Vernonia herbacea, another local species present in the rock fields of Cerrado ${ }^{29,41}$. The dry season (during which the soil moisture levels were lower; Fig. 3C) was characterized by the accumulation of more complex fructans (Fig. 7). In general, complex fructans (containing up to 22 fructose units) were higher during the dry and DR periods. Fructans with lower DP were predominant during the Veranico and rainy periods (Figs. 6B and 7). These contrasting patterns are consistent with the involvement of fructans in drought strategies: complex fructans represent a carbon source that supports initial growth or regrowth during the beginning of the rainy season $^{26,40}$. Simple fructans in the rainy and Veranico periods can be explained by the water-favorable condition for synthesis and turnover of the energy metabolism in the rainy season or a strategy to support osmoregulation during the Veranico.

The accumulation of sugar alcohols such as arabitol and ribitol in the leaves during the dry season (Fig. 8) suggests their involvement in the non-photochemical quenching during drought ${ }^{42}$. However, other simple sugars (e.g., glucose, fructose) may also play a role in drought tolerance in plants by reducing the effects of osmotic stress, maintaining turgor, stabilizing cell membranes, and protecting plants from damage ${ }^{43}$. The level of xylose was also high in the dry season, and it is a component of cell wall metabolism and suggested to be involved in drought stress through cell wall modification ${ }^{35}$. 
Accumulation of phenolic metabolites during the dry and Veranico seasons was observed. The phenylpropanoid pathway was more pronounced during Veranico, resulting in the accumulation of sinapinic acid, sinapyl alcohol, 1-O-(4-coumaroyl)-B-D-glucoside, feruloyl-glucoside, and caffeoylshikimate as well as different flavonoids, which is in contrast to the accumulation of benzoic acid derivatives like vanillic acid and 1-galloyl b-d-glucose during the dry season (Fig. 8). Such accumulation of phenolic metabolites in both seasons might be related to plant protection against oxidative damage that occurs during these two periods of low water availability ${ }^{21,45}$. The production of reactive oxygen species may be the most important secondary effect of drought and can result in chloroplast membrane damage. We observed the accumulation of several galactolipids during Veranico. These lipids are major components of the photosynthetic apparatus ${ }^{46}$.

Pigments like carotenes can act as antioxidants and energy quenchers ${ }^{47}$. Carotenes and xanthophylls, as well as chlorophyll metabolites like chlorophyllide, pheophorbide and pheophytin, were accumulated in the plants during Veranico (Fig. 8). Pheophytin is involved in the process of electron transfer in PS II, working as a bridge of electrons between the chlorophyll P680 and plastoquinone ${ }^{48,49}$. Previous studies have investigated how this mechanism works and the function of pheophytin ${ }^{50,51}$. In this study, the increased levels of pheophytin may be due to induced chlorophyll degradation ${ }^{52}$, the stress, or a response that benefits the plant. However, no chlorophyll changes were observed in the plants collected during Veranico. Therefore, pheophytin accumulation may be a mechanism that helps in photosynthesis efficiency by either acting in the flux of electrons or protecting the system from damage ${ }^{50,53}$. The role of pheophytin in plants is not well understood and needs to be studied under stress conditions.

It is important for a plant to adapt to yearly (long-term) and short-term changes in drought and other environmental factor to coordinate growth and stress-related responses. Stomatal closure acts by reducing the loss of water and maintaining the hydration state in the tissues, but it also limits $\mathrm{CO}_{2}$ influx for photosynthesis. $G$. agrestis is a $\mathrm{C} 4$ plant $^{54}$ and therefore exhibits efficient photosynthetic metabolism under drought conditions. Probably the plant showed high photosynthesis rates in the Veranico period, even with stomatal control. This strategy is important under mild or short-term water stress conditions because the plant can sustain growth, which is primarily affected. The adaptions of metabolism, as observed in the present study, suggests strategies to maintain photosynthesis during the Veranico period. This is of great importance to G. agrestis because this period coincides with the flowering time (Fig. 2), which requires high quantities of assimilated carbon. The minimum hydration necessary for survival, cell enlargement, or maintenance of metabolic activity is provided by regulated stomata control and other associated strategies, such as osmoregulation.

\section{Conclusions}

In this study, we used a metabolomic approach to understand and describe the metabolic adaption of a native species to seasonal changes in drought. We showed that fructans are accumulated in the thickened roots, suggesting a metabolic pattern that is consistent with the storage of carbons during the water-favorable season to support energy demand during the long period of drought and regrowth as well as metabolic adjustments for osmoregulation. In the leaves, ABA, simple sugars, sugar alcohols, phenolics, and pigment metabolism indicate the importance of metabolic responses that should act together to modulate general physiological adaptations such as stomatal control, photosynthesis, and oxidative stress. The metabolic pattern in the Veranico period suggests that during short-term drought, the maintenance of active photosynthesis seems to be more important, and stomatal control, osmoregulation, and protection from oxidative damage may be the strategies used by the species.

\section{Methods}

Geographical location. The study was conducted in the Environmental Preservation Area "Serra do Resplandecente Encantado", a public area in the municipality of Itacambira, north of Minas Gerais State $\left(16^{\circ} 59^{\prime} 47^{\prime \prime}\right.$ $\left.\mathrm{S}, 43^{\circ} 20^{\prime} 01^{\prime \prime} \mathrm{W}\right)$, Brazil. In this area, which is part of the Espinhaço mountain range, rock-field formations are predominant.

Plant material and sampling. The study was conducted in accordance with relevant guidelindes and brazilian legislation ${ }^{55}$. Plant collection was registered in SisGen (Sistema Nacional de Gestão do Patrimônio Genético e do Conhecimento Tradicional) with registration code AFBE204, in October 2018. Specimens of G. agrestis Mart. were collected, properly identified by the PhD Maria Salete Marchioretto, herborized and deposited (voucher number-PACA 114593) at Herbarium Anchieta/PACA (Anchietano Research Instiutute/UNISINOS, São Leopoldo- RS, Brazil). The sampling was conducted in two periods to understand and describe the transition between the dry and rainy seasons. The first period was from September to November 2013, which includes the end of the dry season and beginning of the rainy season, and the second period was from February in the rainy season to July 2014, which already corresponds to the dry season. Sixteen field expeditions were conducted, and six plants (of similar size and development stage) were collected each time, totalizing 96 individual plants sampled. The plants were conditioned in plastic bags and maintained in a Styrofoam box prior to transport to the laboratory. The leaves and roots were immediately frozen in liquid nitrogen, ground, freeze-dried, and stored in a freezer $\left(-20^{\circ} \mathrm{C}\right)$ until analysis. The climate data were obtained from the National Institute of Meteorology (INMET), Brazil (http://www.inmet.gov.br), to characterize the local climate during the sampling. The study was conduct on a single year because later studies ${ }^{22,41}$ in the area/region has shown stability and reproducibility of the data along the years.

Phenology annotation. In each expedition, 30 plant individuals were randomly photographed, and each photograph was analyzed to identify the presence or absence of phenological stages: (1) sprouting, emission of 
new branches and leaves; (2) flowering, presence of floral branches and inflorescences with reddish floral parts; (3) fruiting, presence of inflorescences with senescent floral parts and paleaceous coloration; and (4) dormancy, presence of floral branches and older leaves of the branch in senescence.

Relative water content. To characterize the water status of the plants, 10 leaves and root fragments were collected from each plant and weighed for determining the fresh weight (FW). Then, they were immersed in distilled water for $6 \mathrm{~h}$ to determine the turgid weight (TW), followed by drying at $70{ }^{\circ} \mathrm{C}$ to determine the dry weight (DW). The relative water content (RWC) was estimated using the following equation: RWC $(\%)=[(\mathrm{FW}-\mathrm{DW}) /$ $(\mathrm{TW}-\mathrm{DW})] \times 100^{56}$.

Soil moisture. Soil moisture (Sm, \%) was measured using the gravimetric method ${ }^{57}$. In each field expedition, six soil samples were collected between 0 and $20 \mathrm{~cm}$, which corresponds to the effective root depth. The soil samples were weighed to determine FW and then dried at $70^{\circ} \mathrm{C}$ to measure DW. Sm (\%) was determined using the following formula: $\mathrm{Sm}(\%)=(\mathrm{FW}-\mathrm{DW} / \mathrm{DW}) \times 100$.

Metabolite measurements. Leaves and roots from 11 expeditions (66 plants) were selected (Fig. 1) for the metabolite profiling by using different approaches such as untargeted metabolomic (GC-QTOF MS and LCQTOF MS) and lipidomic analyses (LC-Qtof MS) and targeted (LC-QqQ MS) analysis of amino acids, fructans, and abscisic acid (ABA).

Extractions. For the untargeted metabolomic and amino acid analysis, $10 \mathrm{mg}$ of dried and ground leaves and roots were extracted ${ }^{58}$. For the lipidomic analysis, $10 \mathrm{mg}$ of the dried samples was extracted with $500 \mu \mathrm{L}$ of chloroform:methanol $(2: 1, \mathrm{v} / \mathrm{v})$. After vigorous shaking, $100 \mu \mathrm{L}$ of $\mathrm{NaCl}(0.15 \mathrm{M})$ was added and let to stand for $30 \mathrm{~min}$ for phase separation and then centrifuged (14,000 rpm for $3 \mathrm{~min}$ ). The chloroform phase was collected for analysis. For fructans, $20 \mathrm{mg}$ of the samples was extracted with $500 \mu \mathrm{L}$ of boiling Milli-Q water. After $15 \mathrm{~min}$ at $90^{\circ} \mathrm{C}$, the extracts were cooled down to room temperature and centrifuged (14,000 rpm for $\left.2 \mathrm{~min}\right)$. The supernatant was collected and filtered with 22 micron filters and immediately used for analysis. ABA was extracted from $20 \mathrm{mg}$ of the samples in $1 \mathrm{~mL}$ of $80 \%$ methanol, containing $1 \mathrm{pg} / \mu \mathrm{L}$ of deuterated abscisic acid (d6-ABA), purchased from OlChemIm (Olomouc, Czech Republic). After vigorous shaking, the samples were centrifuged $(14,000 \mathrm{rpm}$ for $10 \mathrm{~min})$, and the supernatant was collected and vacuum-dried. Then, the pellets were recovered in $200 \mu \mathrm{L}$ of $10 \%$ methanol (containing $1 \%$ acetic acid) and purified in SPE columns (Oasis HLB, $30 \mu \mathrm{m}-$ Waters).

Untargeted metabolomic analysis with GC-TOF MS. The extracts were derivatized overnight in room temperature with $30 \mu \mathrm{L}$ methoxyamine ( $15 \mathrm{ng} / \mu \mathrm{L}$ pyridine), and thereafter with $30 \mu \mathrm{L}$ MSTFA with $1 \%$ TMCS for $1 \mathrm{~h}$ in room temperature for $1 \mathrm{~h} .30 \mu \mathrm{L}$ of methyl stearate $(15 \mathrm{ng} / \mu \mathrm{L}$ in heptane) were added before analysis. $0.5 \mu \mathrm{L}$ of the derivatized sample was injected in splitless mode by a L-PAL3 autosampler (CTC Analytics AG, Switzerland) into an Agilent 7890B gas chromatograph equipped with a $10 \mathrm{~m} \times 0.18 \mathrm{~mm}$ fused silica capillary column with a chemically bonded $0.18 \mu \mathrm{m}$ Rxi-5 Sil MS stationary phase (Restek Corporation, U.S.) The injector temperature was $270{ }^{\circ} \mathrm{C}$, the purge flow rate was $20 \mathrm{~mL} / \mathrm{min}$ and the purge was turned on after $60 \mathrm{~s}$. The gas flow rate through the column was $1 \mathrm{~mL} / \mathrm{min}$, the column temperature was held at $70^{\circ} \mathrm{C}$ for $2 \mathrm{~min}$, then increased by $40{ }^{\circ} \mathrm{C} / \mathrm{min}$ to $320^{\circ} \mathrm{C}$, and held there for $2 \mathrm{~min}$. The column effluent was introduced into the ion source of a Pegasus BT timeof-flight mass spectrometer, GC/TOFMS (Leco Corp., St Joseph, MI, USA). The transfer line and the ion source temperatures were $250{ }^{\circ} \mathrm{C}$ and $200^{\circ} \mathrm{C}$, respectively. Ions were generated by a $70 \mathrm{eV}$ electron beam at an ionization current of $2.0 \mathrm{~mA}$, and 30 spectra/s were recorded in the mass range $\mathrm{m} / z 50-800$. The acceleration voltage was turned on after a solvent delay of $150 \mathrm{~s}$. In addition an alkane mixture (C12-C40) was analysed to determine the retention indices of the detected compounds ${ }^{59}$. The generated spectral files were converted to NetCDF format and processed using in-house scripts for MATLAB ver. 8.1 (Mathworks, Natwick, MA, USA). The detected peaks were identified by comparison of mass spectra and retention indexes using NIST MS Search v.2.0 search by inhouse and NIST98 spectral databases.

Untargeted metabolomic and fructans analyses with LC-QTOF MS. The chromatographic separation for untargeted and fructans LC-MS analyses ${ }^{60}$ was performed on an Agilent 1290 Infinity UHPLC-system (Agilent Technologies, Waldbronn, Germany). $2 \mu \mathrm{L}$ of re-suspended aliquots of extracted plasma or plant sample were injected onto an Acquity UPLC HSS T3, $2.1 \times 50 \mathrm{~mm}, 1.8 \mu \mathrm{m} \mathrm{C18} \mathrm{column} \mathrm{in} \mathrm{combination} \mathrm{with} \mathrm{a} 2.1 \mathrm{~mm} \times 5 \mathrm{~mm}, 1.8 \mu \mathrm{m}$ VanGuard precolumn (Waters Corporation, Milford, MA, USA) held at $40{ }^{\circ} \mathrm{C}$. The gradient elution buffers were A (H2O, 0.1\% formic acid) and B (75/25 acetonitrile: 2-propanol, $0.1 \%$ formic acid), and the flow-rate was $0.5 \mathrm{~mL} / \mathrm{min}$. The compounds were eluted with a linear gradient consisting of $0.1-10 \% \mathrm{~B}$ over $2 \mathrm{~min}$, B was increased to $99 \%$ over $5 \mathrm{~min}$ and held at $99 \%$ for $2 \mathrm{~min}$; B was decreased to $0.1 \%$ for $0.3 \mathrm{~min}$ and the flow-rate was increased to $0.8 \mathrm{~mL} / \mathrm{min}$ for $0.5 \mathrm{~min}$; these conditions were held for $0.9 \mathrm{~min}$, after which the flow-rate was reduced to $0.5 \mathrm{~mL} / \mathrm{min}$ for $0.1 \mathrm{~min}$ before the next injection.

The compounds were detected with an Agilent 6550 Q-TOF mass spectrometer equipped with a jet stream electrospray ion source operating in positive or negative ion mode. The settings were kept identical between the modes, with exception of the capillary voltage. A reference interface was connected for accurate mass measurements; the reference ions purine $(4 \mu \mathrm{M})$ and HP-0921 (Hexakis $(1 \mathrm{H}, 1 \mathrm{H}, 3 \mathrm{H}$-tetrafluoropropoxy phosphazine) $(1 \mu \mathrm{M})$ were infused directly into the MS at a flow rate of $0.05 \mathrm{~mL} / \mathrm{min}$ for internal calibration, and the monitored ions were purine $\mathrm{m} / z 121.05$ and $\mathrm{m} / z$ 119.03632; HP-0921 $\mathrm{m} / z 922.0098$ and $\mathrm{m} / z 966.000725$ for positive and negative mode respectively. The gas temperature was set to $150{ }^{\circ} \mathrm{C}$, the drying gas flow to $16 \mathrm{~L} / \mathrm{min}$ and the 
nebulizer pressure $35 \mathrm{psig}$. The sheath gas temp was set to $350^{\circ} \mathrm{C}$ and the sheath gas flow $11 \mathrm{~L} / \mathrm{min}$. The capillary voltage was set to $4000 \mathrm{~V}$ in positive ion mode, and to $4000 \mathrm{~V}$ in negative ion mode. The nozzle voltage was $300 \mathrm{~V}$. The fragmentor voltage was $380 \mathrm{~V}$, the skimmer $45 \mathrm{~V}$ and the OCT $1 \mathrm{RF}$ Vpp $750 \mathrm{~V}$. The collision energy was set to $0 \mathrm{~V}$. The $\mathrm{m} / \mathrm{z}$ range was $70-1700$, and data was collected in centroid mode with an acquisition rate of $4 \mathrm{scans} / \mathrm{s}$ (1977 transients/spectrum). For metabolite annotation autoMSMS was performed on pooled QC-samples at 3 different collision energies, 10, 20 and $40 \mathrm{eV}$.

The fructans compounds were detected with an Agilent 6550 QTOF mass spectrometer equipped with a Jet Stream electrospray ion source operating in positive and negative ion mode ${ }^{60}$. The MS/MS spectra were obtained under the same conditions, with the collision energy from 10 to $40 \mathrm{~V}$.

All generated files were processed using Profinder B.08.00 (Agilent Technologies). The metabolomic data have been deposited to the EMBL-EBI MetaboLights public repository (https://www.ebi.ac.uk/metabolights/ MTBLS613).

Lipidomic analysis with LC-QTOF MS. The lipid analysis was performed in the positive ion mode ${ }^{61}$. In brief, lipid extracts based on chloroform/methanol extraction was chromatographic separation was performed on an Acquity UPLC CSH, $2.1 \times 50 \mathrm{~mm}, 1.7 \mu \mathrm{m} \mathrm{C18}$ column in combination with a $2.1 \mathrm{~mm} \times 5 \mathrm{~mm}$, $1.7 \mu \mathrm{m}$ VanGuard precolumn (Waters Corporation, Milford, MA, USA) held at $60{ }^{\circ} \mathrm{C}$. The gradient elution buffers were A (60:40 acetonitrile:water, $10 \mathrm{mM}$ ammonium formate, $0.1 \%$ formic acid) and B (89.1:10.5:0.4 2-propanol:acetonitrile:water, $10 \mathrm{mM}$ ammonium formate, $0.1 \%$ formic acid), and the flow-rate was $0.5 \mathrm{~mL} /$ min. The compounds were detected with an Agilent 6550 Q-TOF mass spectrometer equipped with a jet stream electrospray ion source operating in positive ion mode. All mass spectrometer settings as for untargeted LC-MS analysis. All generated files were processed using Profinder B.08.00 (Agilent Technologies).

Metabolite annotation. The metabolites were annotated by manual interpretation of the high mass accuracy of the fragments produced by MS/MS experiments and/or comparison with public (Kegg and PlantCyc) and in house database. Additional MS/MS networking (Global Natural products social molecular networking ${ }^{62}$ ) was performed as a quality control to detect adduct masses that somehow were not excluded during the processing data. For annotation of fructans, the degree of polymerization, which means the number of fructose units in the molecule structure was used. Glycerolipids annotation was performed by comparison with in house lipid spectral databases. The lipid classes were differentiated by the presence of diagnostic fragments $\mathrm{m} / z 184.0733$ (PC), $\mathrm{m} / z 243.0945$ (MGDG-Na ${ }^{+}$) or neutral losses of 162.0528 (DGDG), 161.0450 (PI) and 141.0191 (PE). Spectral information of phenolics and lipids are presented in Supplementary Tables 5 and 7.

Amino acid analysis with LC-QqQ MS. The extracts were derivatized with the Waters AccQ•Tag method, in accordance with the manufacturer's protocol. The analysis was performed using a 1290 Infinitely UHPLC system from Agilent Technologies (Waldbronn, Germany) with G4220A binary pump, G1316C thermostated column compartment, and G4226A autosampler with G1330B autosampler thermostat coupled to an Agilent 6490 triple quadrupole mass spectrometer equipped with a jet stream electrospray source operating in the positive ion mode $^{63}$. The amino acid multiple-reaction-monitoring (MRM) transitions were optimized using MassHunter MS Optimizer software (Agilent Technologies Inc., Santa Clara, CA, USA), and the data were quantified using MassHunter Quantitation software B07.01 (Agilent Technologies); the amount of each amino acid was calculated on the basis of the calibration curves.

ABA analysis with LC-QqQ MS. For the ABA analysis ${ }^{64}$ the analytes were separated using a 1290 UHPLC system from Agilent Technologies (Waldbronn, Germany), with a G4220A binary pump, G1316C thermostated column compartment, and G4226A autosampler with thermostat. A $2 \mu \mathrm{L}$ aliquot of the sample was injected onto a Waters column (TSS3, C18; $2.1 \times 50 \mathrm{~mm}, 1.7 \mu \mathrm{m}$ ) at $40^{\circ} \mathrm{C}$ in a column oven. The analysis was performed in multiple-reaction-monitoring (MRM) mode, in which the fragmentation conditions for the analyses were optimized using MassHunter MS Optimizer software (Agilent Technologies Inc., Santa Clara, CA, USA). MRM scan was performed monitoring $m / z 263 \rightarrow 153$ for ABA and $\mathrm{m} / \mathrm{z} 269 \rightarrow 159$ for d6-ABA as quantifiers. Transitions $\mathrm{m} / z 263 \rightarrow 219$ for ABA and $\mathrm{m} / z 269 \rightarrow 225$ for d6-ABA were used as qualifier ions. The data were quantified using MassHunter Quantitation software B07.01 (Agilent Technologies); the amount of ABA was calculated on the basis of the calibration curve done with d6-ABA $(1 \mathrm{pg} / \mu \mathrm{L})$ and ABA standards (from 0 to $10 \mathrm{pg}$ ).

Statistical analysis. The generated datasets from the different analyses were checked using statistical multivariate analysis in SIMCA-P 13 software (Umetrics AB, Umeå, Sweden). The samples were compared using PCA and OPLS-DA analysis. Before the analysis, the missing data were set to the mean value of each variable and were mean-centered and scaled to the unit variance. The samples were grouped according to the environment characterization into five groups: 1, dry (D: 12 samples); 2, transition between dry to rainy (DR: 18 samples); 3 , "Veranico", a short dry period during the rainy season (V: 6 samples); 4, rainy (R: 12 samples); and 5, transition between rainy to dry (RD: 18 samples). To identify the most important metabolites in the OPLS-DA models, the VIP was used, and variables showing VIP values greater than 1 were considered of high importance ${ }^{65}$. The OPLS-DA models were validated using the goodness of fit $\left(\mathrm{R}^{2}\right)$ and prediction (Q2) parameters. Further statistical analysis and visualization (ANOVA, Tukey's test, $t$-test, Benjamini and Hochberg correction, and heatmaps) were performed using R-software version 3.4.166. 
Received: 23 December 2020; Accepted: 3 June 2021

Published online: 21 June 2021

\section{References}

1. Ratter, J. A., Ribeiro, J. F. \& Bridgewater, S. The brazilian cerrado vegetation and threats to its biodiversity. Ann. Bot. 80, 223-230 (1997).

2. Mittermeier, R. A. et al. Hotspots revisited: Earth's biologically richest and most endangered terrestrial ecoregions 2 nd edn. (University of Chicago Press, 2005).

3. Bustamante, M. M. C. et al. Potential impacts of climate change on biogeochemical functioning of Cerrado ecosystems. Braz. J. Biol. 7, 655-671 (2012).

4. Benites, V. M., Schaefer, C. E. G. R., Simas, F. N. B. H. \& Santos, G. Soils associated with rock outcrops in the Brazilian mountain ranges Mantiqueira and Espinhaço. Rev. Bras. Bot. 30, 569-577 (2007).

5. Rapini, A., Ribeiro, P. L. \& Lambert, S. A flora dos campos rupestres da Cadeia do Espinhaço. Megadiversidade 4, 8-24 (2008).

6. Mucina, L. Vegetation of Brazilian campos Rupestres on siliceous substrates and their global analogues. Flora https://doi.org/10. 1016/j.flora.2017.06.007 (2017).

7. Miola, D. T. B. \& Fernandes, G. W. Growing straight versus growing decumbent: Soil quality and allometry in Syagrus glaucescens Becc. (Arecaceae), an endemic and threatened palm of the Espinhaço Mountains, Brazil. Acta Bot. Bras. 29, 417-424 (2015).

8. Silveira, F. A. et al. Ecology and evolution of plant diversity in the endangered campo rupestre: A neglected conservation priority. Plant Soil 403, 129-152 (2016).

9. Lisar, S. Y. S., Motafakkerazad, R., Hossain, M. M. \& Ismail, M. M. R. Water stress in plants: Causes, effects and responses. In Water stress (eds. Ismail M. M. R., Hiroshi H.) (IntechOpen, Rijeka). https://doi.org/10.5772/39363. https://www.intechopen.com/books/ water-stress/water-stress-in-plants-causes-effects-and-responses (2012). Accessed 15 Jan 2018.

10. Turner, N. C. Adaptation to water deficits: A changing perspective. Aust. J. Plant Physiol. 13, 175-190 (1986).

11. Volaire, F. A unified framework for plant adaptive strategies to drought: Across scales and disciplines. Glob. Change Biol. 00, 1-10. https://doi.org/10.1111/gcb.14062 (2018).

12. Flexas, J. et al. Decreased Rubisco activity during water stress is not induced by decreased relative water content but related to conditions of low stomatal conductance and chloroplast $\mathrm{CO}_{2}$ concentration. New Phytol. 172, 73-82 (2006).

13. Cornic, G. \& Fresneau, C. Photosynthetic carbon reduction and carbon oxidation cycles are the main electron sinks for Photosystem II activity during a mild drought. Ann. Bot. 89, 887-894 (2002).

14. Ping, M. A., Tuan-hui, B. A. I. \& Feng-wang, M. A. Effects of progressive drought on photosynthesis and partitioning of absorbed light in apple trees. J. Int. Agric. 14, 681-690 (2015).

15. Buchner, O. et al. Drought affects the heat-hardening capacity of alpine plants as indicated by changes in xanthophyll cycle pigments, singlet oxygen savengind, a-tocopherol and plant hormones. Environ. Exp. Bot. 133, 159-175 (2017).

16. Takahashi, S. \& Badger, M. R. Photoprotection in plants: A new light on photosystem II damage. Trends Plant Sci. 16, 53-60 (2011).

17. Porembski, S. \& Barthlott, W. On the occurrence of a velamen radicum in Cyperaceae and Velloziaceae. Nordic J. Bot. 15, 625-629 (1995).

18. Nishi, A. H., Vasconcellos-Neto, J. \& Romero, G. Q. The role of multiple partners in a digestive mutualism with a protocarnivorous plant. Ann. Bot. 11, 43-150 (2013).

19. Martin, C. E. \& von Willert, D. J. Leaf epidermal hydathodes and the ecophysiological consequences of foliar water uptake in species of Crassula from the Namib Desert in Southern Africa. Plant Biol. 2, 229-242 (2000).

20. Joaquim, E. O., Silva, T. M., Figueiredo-Ribeiro, R. C. L., Moraes, M. G. \& Carvalho, M. A. M. Diversity of reserve carbohydrates in herbaceous species from Brazilian campo rupestre reveals similar functional traits to endure environmental stresses. Flora https:// doi.org/10.1016/j.flora.2017.01.001 (2017).

21. Lopes-Mattos, K. L. B., Azevedo, A. A., Soares, A. A. \& Meira, R. M. S. A. Underground system of Mandevilla atroviolacea (Stadelm.) Woodson (Apocynaceae, Apocynoideae) from the Brazilian high-altitude grassland. S. Afr. J. Bot. 87, 27-33 (2013).

22. Silva, F. G. D., Cangussu, L. M. B., Paula, S. L. A. D., Melo, G. A. \& Silva, E. A. Seasonal changes in fructan accumulation in the underground organs of Gomphrena marginata Seub. (Amaranthaceae) under rock-field conditions. Theor. Exp. Plant Physiol. 25, 46-55 (2013).

23. Carvalho, M. A. M. \& Dietrich, S. M. C. Variation in fructan content in the undergound organs of Vernonia herbacea (Vell.) Rusby at different phenological phases. New Phytol. 123, 735-740 (1993).

24. Neves, S. P. S. \& Conceição, A. A. Campo rupestre recem queimado na Chapada Diamantina, Bahia, Brasil: plantas de rebrota e sementes, com espécies endêmicas na rocha. Acta Bot. Bras. 24, 97-707 (2010).

25. Wheeler, T. \& Von Braun, J. Climate change impacts on global food security. Science 341, 508-513 (2013).

26. Riediger, J., Breckling, B., Svoboda, N. \& Schröder, W. Modelling regional variability of irrigation requirements due to climate change in Northern Germany. Sci. Total Environ. 541, 329-340 (2016).

27. Bindi, M. \& Olessen, J. E. The response of agriculture in Europe to climate changes. Reg. Environ. Change 11, 151-158 (2011).

28. Marengo, J. A. et al. Climate Change in Central and South America: Recent Trends, Future Projections, and Impacts on Regional Agriculture. CCAFS Working Paper no. 73. CGIAR Research Program on Climate Change, Agriculture and Food Security (CCAFS). Copenhagen, Denmark. www.ccafs.cgiar.org (2014). Accessed 7 Nov 2019.

29. Tian, H., Lam, S. M. \& Shui, G. Metabolomics, a powerful tool for agricultural research. Int. J. Mol. Sci. 17, 1871 (2016).

30. Wani, S. H., Dutta, T., Neelapu, N. R. R. \& Surekha, C. Transgenic approaches to enhance salt and drought tolerance in plants. Plant Gene 11, 219-231 (2017).

31. Siqueira, J. C. O gênero Gomphrena L. (Amaranthaceae) no Brasil. Tese de doutorado. (Universidade Estadual de Campinas, 1991).

32. Petridis, A., Therios, I., Samouris, G., Koundouras, S. \& Giannakoula, A. Effect of water deficit on leaf phenolic composition, gas exchange, oxidative damage and antioxidant activity of four Greek olive (Olea europaea L.) cultivars. Plant Physiol. Biochem. 60, $1-11(2012)$.

33. Bauer, H. et al. The stomatal response to reduced relative humidity requires guard cell-autonomous ABA synthesis. Curr. Biol. 23, 53-57 (2013).

34. Escalona, J. M. et al. Responses of leaf night transpiration to drought stress in Vitis vinifera L. Agric. Water Manag. 118, 50-58 (2013).

35. McAdam, S. A. M., Manzib, M., Rossa, J. J., Brodribba, T. J. \& Gomez-Cadenasb, A. Uprooting an abscisic acid paradigm: Shoots are the primary source. Plant Signal. Behav. https://doi.org/10.1080/15592324.2016.1169359 (2017).

36. Yan, F., Li, X. \& Liu, F. ABA signaling and stomatal control in tomato plants exposure to progressive soil drying under ambient and elevated atmospheric $\mathrm{CO}_{2}$ concentration. Environ. Exp. Bot. 139, 99-10 (2017).

37. Daszkowska-Golec, A. The role of abscisic acid in drought stress: How ABA helps plants to cope with drought stress. In Drought Stress Tolerance in Plants Vol. 2 (eds Hossain, M. et al.) (Springer, 2016).

38. Seki, M., Umezawa, T., Urano, K. \& Shinozaki, K. Regulatory metabolic networks in drought stress responses. Curr. Opin. Plant Biol. 10, 292-302 (2007).

39. Sah, S. K., Reddy, K. R. \& Li, J. Abscisic acid and abiotic stress tolerance in crop plants. Front. Plant Sci. 7, 1-26 (2016). 
40. Versluys, M., Kirtel, O., Oner, T. E. \& Van den Ende, W. The fructan syndrome: Evolutionary aspects and common themes among plants and microbes. Plant Cell Environ. 41, 16-38 (2018).

41. Cangussu, L. M. B. Variação sazonal do acúmulo de frutanos em Vernonia herbacea (Vell.) Rusby sob condições de campo rupestre. Dissertação de mestrado. (Universidade Estadual de Montes Claros, 2012).

42. Kosugi, M. et al. Arabitol provided by lichenous lungi enhances ability to dissipate excess light energy in a symbiotic green alga under desiccation. Plant Cell Physiol. 54, 1316-1325 (2013).

43. Bowne, J. B. et al. Drought responses of leaf tissues from wheat cultivars of differing drought tolerance at the metabolite level. Mol. Plant 5, 418-429 (2012).

44. Mibei, E. K., Owino, W. O., Ambuko, J., Giovannonic, J. J. \& Onyangoa, A. N. Metabolomic analyses to evaluate the effect of drought stress on selected african eggplant accessions. J. Sci. Food Agric. 98, 205-216 (2018).

45. Agati, G. et al. Functional roles of flavonoids in photoprotection: New evidence, lessons from the past. Plant Physiol. Biochem. 72, 5-45 (2013).

46. Hölsl, G. \& Dörmann, P. Structure and fuction of glycoglycerolipis in plants and bacteria. Prog. Lipid Res. 46, 225-243 (2007).

47. Dilbeck, P. L. et al. Quenching capabilities of long-chain carotenoids in light-harvesting-2 complexes from Rhodobacter sphaeroides with an engineered crotenoid synthesis pathway. J. Phys. Chem. 120, 5429-5443 (2016).

48. Klimov, V. V. Discovery of pheophytin function in the photosynthetic energy conversion as the primary electron acceptor of Photosystem II. Photosynth. Res. 76, 247-253 (2003).

49. Krieger-Liszkay, A., Fufezan, C. \& Trebst, A. Singlet oxygen production in photosystem II and related protection mechanism. Photosynth. Res. 98, 551-564 (2008).

50. Sugiura, M. et al. Modification of the pheophytin redox pontential in Thermosynechococcus elongates Photosystem II with PsbA3 as D1. Biochim. Biophys. Acta 1837, 139-148 (2014).

51. Guerra, F., Adam, S. \& Bondar, A. N. Revised force-paramenters for chlorophyll- $a$ pheophytin- $a$ and plastoquinone-9. J. Mol. Graph. Model. 58, 30-39 (2015).

52. Schelbert, S. et al. Pheophytin pheophorbide hydrolase (Pheophytinase) is involved in chlorophyll breakdown during leaf senescence in Arabidopsis. Plant Cell 21, 767-785 (2009).

53. Vass, I. \& Cser, K. Janus-faced charge recombinations ins photosystem II photoinhibition. Trends Plant Sci. 14, 200-205 (2009).

54. Sage, R. F., Sage, T. L., Pearcy, R. W. \& Borsch, T. The taxonomic distribution of $\mathrm{C}_{4}$ photosynthesis in Amaranthaceae sensu stricto. Am. J. Bot. 94, 1992-2003 (2007).

55. BRASIL. Lei $n^{\circ} 13.123$, de 20 de maio de 2015. Regulamenta o inciso II do $\$ 1^{\circ}$ e o $\$ 4$ o do art. 225 da Constituição Federal, o Artigo $1^{\circ}$, a alínea j do Artigo $8^{\circ}$, a alínea c do Artigo 10, o Artigo 15 e os $\$ \$ 3^{\circ}$ e $4^{\circ}$ do Artigo 16 da Convenção sobre Diversidade Biológica, promulgada pelo Decreto no 2.519, de 16 de março de 1998; dispõe sobre o acesso ao patrimônio genético, sobre a proteção e o acesso ao conhecimento tradicional associado e sobre a repartição de benefícios para conservação e uso sustentável da biodiversidade; revoga a Medida Provisória no 2.186-16, de 23 de agosto de 2001; e dá outras providências. Diário Oficial da República Federativa do Brasil, Brasília, DF, 14 de maio de 2015.

56. Weatherley, P. E. Studies in the water relations of the cotton plant, I- The field measurements of water deficits in leaves. New Phytol. 49, 81-97 (1950).

57. Blake, G. R. Bulk density. In Methods of Soil Analysis (eds Black, C. A. et al.) 374-390 (American Society of Agronomy, 1965).

58. Gullberg, J., Jonsson, P., Nordström, A., Sjöström, M. \& Moritz, T. Design of experiments: An eficient strategy to identify factors influencing extraction and derivatization of Arabidopsis thaliana samples in metabolomic studies with gas chromatography/mass spectrometry. Anal. Biochem. 331, 283-295 (2004).

59. Schauer, N. et al. GCMS libraries for the rapid identification of metabolites in complex biological samples. FEBS Lett. 579, 13321337 (2005).

60. Abreu, I. N. et al. A metabolite roadmap of the wood-forming tissue in Populus tremula. New Phytol. 228, 1559-1572 (2020).

61. Obudulu, O. et al. A multi-omics approach reveals function of secretory carrier-Aasociated membrane proteins in wood formation of Populus trees. BMC Genom. 19, 1-18 (2018).

62. Wang, M. et al. Sharing and community curation of mass spectrometry data with global natural products social molecular networking. Nat. Biotechnol. 34, 828-837 (2016).

63. Carlsson, J. et al. Interdependence of threonine, methionine and isoleucine metabolism in plants: Accumulation and transcriptional regulation under abiotic stress. Amino Acids 39, 933-947 (2010).

64. Haas, J. C. et al. Candidate regulators and target genes of drought stress in needles and roots of Norway spruce. Tree Physiol https:// doi.org/10.1093/treephys/tpaa178 (2021).

65. Eriksson, L., Kettaneh-Wold, N., Trygg, J., Wikström, C. \& Wold, S. Multiand Megavariate Data Analysis: Part I: Basic Principles and Applications. (Umetrics AB, 2006).

66. R Core Team. R: A Language and Environment for Statistical Computing. (R Foundation for Statistical Computing, 2017). https:// www.R-project.org/. Accessed 04 Mar 2021.

\section{Acknowledgements}

We thank the Coordenação de Aperfeiçoamento de Pessoal de Nível Superior (CAPES), Brazil-PNADB program (to GAM), and Knut \& Alice Wallenberg foundation (to TM) for their financial support. We thank the Swedish Metabolomics Centre for support with the metabolomics analysis.

\section{Author contributions}

G.A.M.; Designed the research, work on sampling, data collection, metabolomics and wrote the manuscript. M.B.O., L.V.S., M.A.S.P; Worked in sampling, data collection and co-wrote the manuscript. I.N.A., I.G.F.B.; Cowork on metabolomics and made a critical review of the manuscript. T.M.; Was responsible for the supervision of the metabolomic analysis and provided a critical review of the manuscript.

\section{Competing interests}

The authors declare no competing interests.

\section{Additional information}

Supplementary Information The online version contains supplementary material available at https://doi.org/ 10.1038/s41598-021-92449-9.

Correspondence and requests for materials should be addressed to G.A.M.

Reprints and permissions information is available at www.nature.com/reprints. 
Publisher's note Springer Nature remains neutral with regard to jurisdictional claims in published maps and institutional affiliations.

(c) (1) Open Access This article is licensed under a Creative Commons Attribution 4.0 International License, which permits use, sharing, adaptation, distribution and reproduction in any medium or format, as long as you give appropriate credit to the original author(s) and the source, provide a link to the Creative Commons licence, and indicate if changes were made. The images or other third party material in this article are included in the article's Creative Commons licence, unless indicated otherwise in a credit line to the material. If material is not included in the article's Creative Commons licence and your intended use is not permitted by statutory regulation or exceeds the permitted use, you will need to obtain permission directly from the copyright holder. To view a copy of this licence, visit http://creativecommons.org/licenses/by/4.0/.

(C) The Author(s) 2021 